\title{
Contributions of the International Space Station towards future exploration missions
}

\author{
Johannes Weppler \\ German Aerospace Center (DLR), Königswinterer Str. 522-524, 53227 Bonn, Germany
}

\section{A R T I C L E I N F O}

\section{Article history:}

Received 24 January 2014

Received in revised form

4 June 2014

Accepted 13 June 2014

Available online 21 June 2014

\section{Keywords:}

ISS

Exploration

MPCV

ESM

Technology

\begin{abstract}
A B S T R A C T
When the idea of a large space station in Low Earth Orbit (LEO) was conceived in the 1980s, it was primarily planned as an orbiting laboratory for microgravity research. Some even thought of it as an industrial plant in space. Whereas the latter did not materialize because of various reasons, the former is absolutely true when you talk about the International Space Station (ISS). Since the transition to a six astronaut crew in 2009 and the completion of its assembly in 2011, it has been intensively used as laboratory in a wide field of scientific topics. Experiments conducted on ISS have yielded first class results in biology, physiology, material science, basic physics, and many more. While its role as a laboratory in space is widely recognized, the awareness for its potential for preparing future exploration missions beyond LEO is just increasing. This paper provides information on how the ISS programme contributes to future exploration efforts, both manned and unmanned. It highlights the work that has been done or is currently underway in the fields of technology, operations, and science. Further potentials and future projects for exploration preparation are also shown. A special focus lies on experiments and projects primarily funded by the German Aerospace Center (DLR) or with strong German participation in the science team.
\end{abstract}

(c) 2014 IAA. Published by Elsevier Ltd. All rights reserved.

\section{Introduction}

For more than 50 years humans have travelled to the heavens above. That time can be divided in a sequence of different phases. The early Space Age was dominated by the so-called Space Race. The fierce competition of the super powers of that time: the United States of America and the Soviet Union. They raced each other in achieving significant firsts in space. At the beginning, in the 1950s and the early 1960s, the Soviet Union successfully achieved a lot of these first: the first artificial satellite (Sputnik, 1957), the first human in orbit (Yuri Gagarin, 1961) and the first spacewalk (Alexei Leonov, 1965). The United States always seemed to be chasing its opponent. But by 1965 the

\footnotetext{
E-mail address: johannes.weppler@dlr.de
}

strengthening of their forces which was accomplished by focusing on the goal of sending a human to the surface of the Moon and brining him safely back, outlayed by President Kennedy in 1961, yielded in NASA passing its Soviet counterpart. A chain of U.S. successes followed: the first rendezvous in space (Gemini 6A, 1965), the extension of mission durations to more than one week (Gemini 5 and Gemini 7, both 1965), and the first docking of two spacecrafts (Gemini 8, 1966). 1967 marked the transition to the Apollo programme. The first launch of the giant Saturn V rocket (Apollo 4, 1967), the first manned mission orbiting the Moon (Apollo 8, 1968) and eventually the successful landing of Neil Armstrong and Buzz Aldrin on the surface of the Moon (Apollo 11, 1969) showed that the U.S. space programme of that time was far ahead of its Soviet counterpart. In the end the Soviet Union had to admit its defeat and the Space Race ended. 
Space stations became en vogue during the 1970s and it was again the Soviet Union which marked some first. The Salyut line of Soviet space stations seemed to be superior to the U.S. Skylab, although it also had to suffer some setbacks from time to time. 1975 was a significant year, as it featured the first close cooperation of the two superpowers in space. During the Apollo Soyuz Test Program (ASTP) the two signature spaceships of the two contenders docked for the first time in history and cosmonauts and astronauts shook hand in orbit. Unfortunately, that remained the only cooperative project until the end of the Cold War.

In the 1980s space operations concentrated on LEO. NASA introduced its new fleet of Space Shuttles, which were designed to serve as short-term orbital laboratories and to dispense and retrieve payloads (e.g. satellites). In 1986 the first modular space station was launched by the Soviet Union. The Mir station should not only prove to be long-lasting, but also to be the venue of a renewed spirit of cooperation in space. With the collapse of the Soviet Union in 1991, the United States and Russia agreed on hosting mixed crews aboard the Mir station and to make it possible to dock the Space Shuttle with the aging orbital complex. The Mir programme yielded a lot of experience in building and operating a large space station and when both Russia and the western nations realized that two separate space stations, Mir 2 and Freedom, would not be sustainable on the long run, an agreement was struck which led to the creation of the ISS programme. Today, 15 nations are participating in the programme with the United Kingdom being the newest participant.

The first building block of this truly International Space Station was launched in 1998 while the old Mir station was still in orbit. The ISS programme also had to endure difficult times when money was tight or after the Space Shuttle Columbia was destroyed when returning to Earth, but in 2011 its construction came to completion with a last Space Shuttle flight (Fig. 1). The participating nations have agreed on operating the stations until 2020 at least. What will come next is still uncertain, but it is obvious that the station should be used to support those steps that lie ahead.

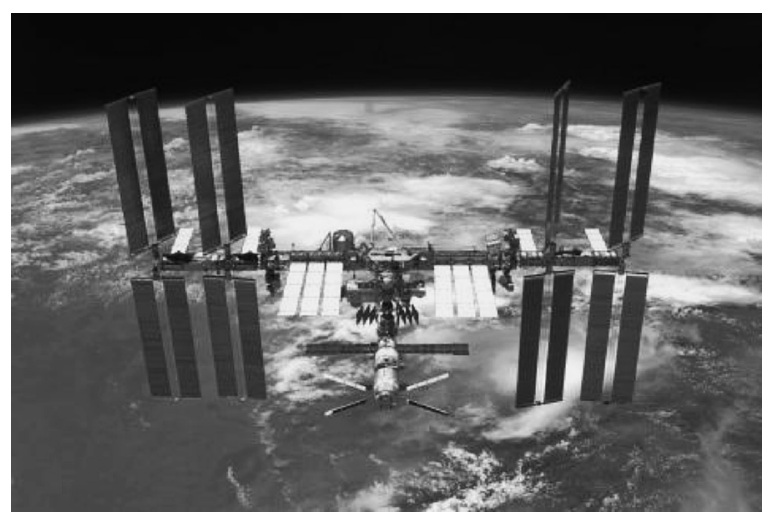

Fig. 1. The ISS as of November 2011.

Source: NASA

\section{Past and current contributions of the ISS programme to future space exploration}

\subsection{Political and organizational framework}

The ISS programme is the first space project with such a broad international cooperation over such a long time. All major space faring nations are involved in the programme. Only the prominent newcomer in space, China is still absent; a fact that might or might not change in the foreseeable future. Globally, the mid-term goal for all human space exploration efforts is to land a crew on the surface of Mars and to bring them back safely. From today's point of view this kind of missions seems to be too big for a single nation to handle; not counting one-shot missions with no broader long-term perspectives. Therefore international cooperation will be necessary to achieve a sustainable exploration programme, which will eventually bring humans to Mars.

The ISS programme is a unique opportunity to practice how to cooperate on big space projects. It shows which processes support efficient multi-national projects and which rather hinder them. The ISS programme has also led to a big set of standards, both technical and operational, that will facilitate cooperation in future projects.

Barter agreements are also an important part of the ISS programme. Instead of paying others to do something, a partner contributes a piece of hardware or a service to offset his obligations. The exchange of funds is minimized. This way all partners can fund significant technology developments within their country. A prime example of how such a barter agreement can even link the ISS programme with future exploration programmes is ESA's decision to provide a service module to the future U.S. crew vehicle. More details about that can be found in chapter 2 of this paper.

The formation of the International Space Exploration Coordination Group (ISECG) is a first effort to foster cooperation in space exploration and to harmonize exploration programmes in order to make the most efficient use of the limited resources. Although ISECG is not part of the ISS programme, it actively promotes the role that the ISS can play in preparing for the future of space exploration.

\subsection{Science}

Gathering new knowledge by conducting first class scientific experiments is probably one of the prime objectives of the ISS programme. A vast majority of these experiments deal with topics in biology, physiology, material science, and fundamental physics. Gaining new insights that will help to improve life on Earth is the major goal of many of them. Nevertheless, there is a significant number of investigations that address topics that are directly related to space exploration. Exposure to radiation and the deteriorating human physique during long duration missions in space are the most important scientific problems that need to be addressed in order to mitigate the hazards to crews of future missions beyond LEO. 
The degeneration of muscles, the cardio-vascular system, and bones are well-known problems of human space missions. A lot of effort has gone into finding the drivers for these unfavourable changes since the days of Salyut and Skylab. Physical exercises, for long, seemed to be the only solution to this problem. The development of sophisticated workout equipment and training schedules is also conducted aboard the ISS today. Maximizing the positive effects on the astronaut's physiological condition while minimizing mass and the disturbances by these devices is the goal of scientists from all over the world. Diversified exercising can also have positive psychological effects on crew members besides the physiological aspect. In addition to the findings that yielded from experiments on physical exercising, a new vantage point on the topic of bone degradation was introduced by the SOLO (Sodium Loading in Microgravity) experiment. Preliminary results from the ISS experiment, which was done by Dr. FringsMeuthen with support from DLR, indicate that high doses of salt in astronauts' meals accelerate the loss of bone mass [1]. Astronauts' diets on long duration missions with long exposure to low gravity levels will be based on the findings of SOLO and similar experiments and will thus help to keep these astronauts healthy and ready to work.

Missions beyond LEO will also bring crews outside the protective shield of Earth's magnetic field. The complex issue of exposure to radiation and its effects on humans will become more important. The DLR Institute of Aerospace Medicine in Cologne conducted the MATROSHKA experiment on ISS in 2004 and 2005. The experiment, which was a cooperation with Russia, featured an artificial torso that was mounted on the Russian segment of the space station for 539 days and later also placed inside the station. The device resembled the upper body of an astronaut in his EVA suit (Fig. 2). Measurements of the radiation dose at different layers of the torso's interior were performed. The experiment will help to understand the effects of space radiation on the human body; an essential factor for long missions to new destinations.

Long distance missions with duration of several months or even years will probably have to bring their supplies along rather than rely on re-supply flights as it is done in the ISS programme today. Plants cultivated by the crew will play an important role as food source. Understanding how plants grow under the influence of altering gravity and the space environment is the topic of a lot of experiments on ISS. The European Modular Cultivation System (EMCS) is one facility that supports this kind of research.

Never before in human history was it possible to do such a multitude of scientific research in an orbital lab that was specifically designed to host large numbers of experiments at the same time. The ISS today has three dedicated laboratory modules: the U.S. Destiny module, the Japanese Kibo module, and the European Columbus module. The Russians will launch their laboratory module Nauka not earlier than the end of 2015. In addition others parts of the station, especially in the Russian segment, are used for scientific research today. As a permanently manned orbital laboratory, the ISS offers unique research opportunities for both enhancing life on Earth and preparing the next steps in space. Some might see astronauts as an unnecessary

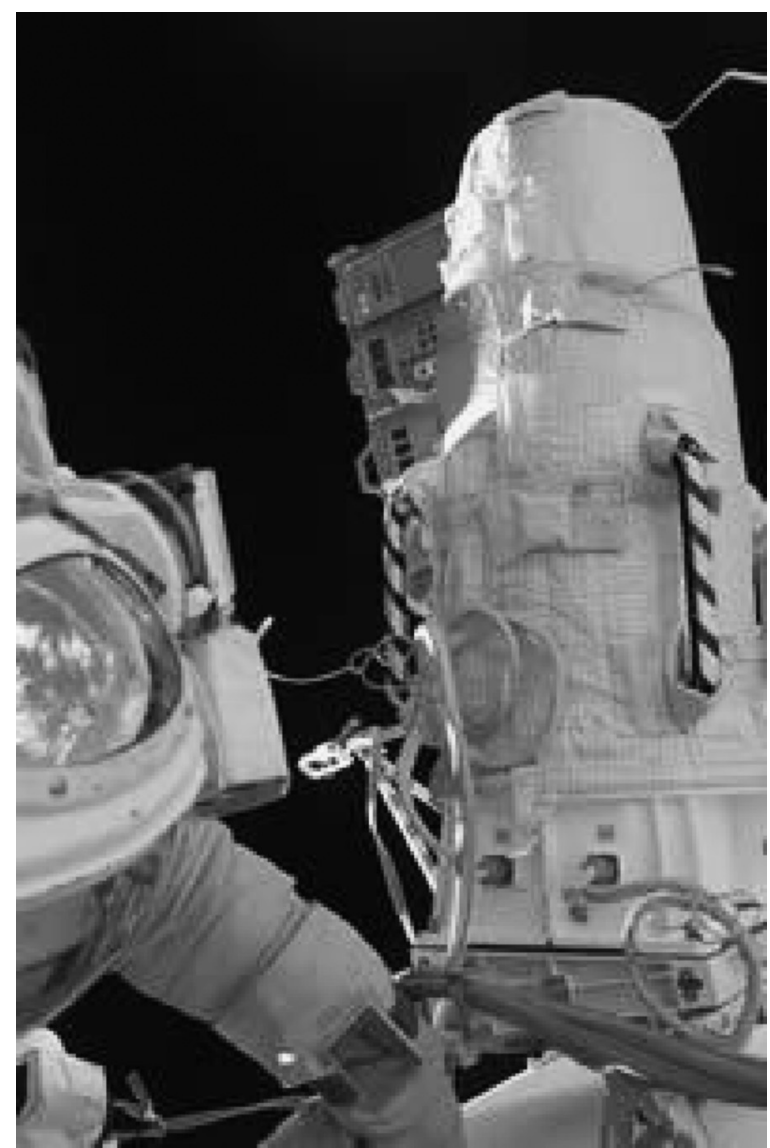

Fig. 2. The MATROSHKA Experiment at ISS

Source: NASA

factor that is just driving costs, but the experience of the ISS programme has shown that their capabilities are needed to keep science going in space. Furthermore meaningful research on human physiology necessitates living subjects, i.e. astronauts. As of March 2013 more than 1500 experiments have been conducted during the history of the ISS or are currently on-going [2]. The scientific utilization has significantly increased since the crew size could be raised to six astronauts in 2009. The addition of another astronaut with the commencing of U.S. commercial crew launches to the station in 2017 will even improve that utilization. Of the more than 200 experiments under ESA regime roughly 40 per cent have a German Principal Investigator (PI) or significant German contributions. This shows Germany's sustained commitment to the future of research on ISS.

\subsection{Technology}

The first U.S. and Soviet space stations consisted of one module only. The Soviet (and later Russian) Mir station, whose first building block was launched in February 1986 , was the first station to consist of multiple modules which were launched separately and subsequently put together in orbit. Each of these modules had a distinct function. Operation of that station and the first cooperative missions 
of the U.S.A. and Russia laid an essential base for the future. Today's ISS dwarfs the former Russian station in dimensions, mass, and complexity. Construction of ISS has been a masterpiece of space engineering and international cooperation. Bringing together modules and equipment from so many different countries and getting them to actually work under the harsh conditions of space has resulted in technological experience that will prove invaluable for the future of space exploration.

Assembly of the space station was a sophisticated sequence of automated dockings as well as station and Space Shuttle supported EVAs that were assisted by robotic means such as the Shuttle Remote Manipulator System (SRMS) also known as Canadarm. It took almost $1000 \mathrm{~h}$ of work during about 160 EVAs to bring the station to today's configuration [3]. Construction of ISS is the prime example of astronaut human cooperation. There should not be a competition between these two aspects, but a partnership. ISS features a variety of exterior robotic assets that support station maintenance, berthing and unloading of unmanned cargo vehicles. The Canadian Space Agency's (CSA) Mobile Servicing System (MSS) with its two components Canadarm2 and Dextre, the Japanese Experiment Module Remote Manipulator System (JEMRMS) and two Russian Strela cargo cranes will be supplemented by ESA's European Robotic Arm (ERA) which will be launched to the station with the new Russian science module. With the emergence of the idea of an exploration gateway station at one of the Earth-Moon-Lagrangian Points (EML), the aspect of tele-operating robotic assets on a planetary surface from an orbiting station has become a new topic. ISS would be the ideal test-bed for such a technology. The Meteron (Multi-purpose End-To-End Robotics Operations Network) project of ESA, DLR, Roscosmos, and NASA did exactly that in a first approach. A successful experiment including a rudimental robotic arm being controlled by a ground station was ROKVISS (Robotik-Komponenten-Verifikation auf der ISS). The DLR Institute of Robotics and Mechatronics in Oberpfaffenhofen built and operated the experiment. It was attached to the exterior of the Russian segment of the station where it performed hundreds of tests which ran flawlessly for more than five years. Inspections after its return to Earth showed that the mechanics were in surprisingly good condition after being exposed to the space environment for such a long time [4]. Robonaut2 and the three SPHERES (Synchronized Position Hold, Engage, Reorient Experimental Satellites) are currently two projects that operate robotic elements inside the station. Robotic assistants could conduct routine maintenance tasks while astronauts are asleep. On 4 February 2011, for example, the Dextre robotic hand unloaded external cargo from HTV-2 being controlled by operators on Earth while astronauts were resting. All these experiences with robotic assets supporting astronauts during their mission will be very valuable for future missions beyond ISS.

So far, the ISS programme has led to the successful development of four new space vehicles: the European Automated Transfer Vehicle (ATV), the Japanese H-II Transfer Vehicle (HTV), and the Dragon cargo carrier of the U.S. company Space Exploration Technologies
(SpaceX). The fourth vehicle, the Cygnus cargo craft of Orbital Science Corporation, had its maiden flight to the space station in September 2013. The backbone of ISS logistics has been the veteran Russian spacecrafts Soyuz and Progress which proved to be very reliable, especially during the time when the U.S. Space Shuttle fleet was grounded due to the Columbia accident. The variety of cargo vehicles created a redundancy which made the ISS programme less prone to failures. Significant know-how in spacecraft development and operation has been build up in all participating nations. Although future missions beyond LEO would probably require substantial modifications to existing vehicles, this knowledge will be utilized for future exploration missions.

Perhaps one of the most important experiences gathered during the ISS programme in preparation for new exploration missions is derived from operating and maintaining the station and its system hardware. The ISS has complex and sophisticated systems in thermal control, energy supply and distribution, data processing and management, and environmental control and life support. Future missions, especially further away from Earth, will need those systems to be operating without flaws. Experience from operating the station's system hardware is one aspect, experiments which test new concepts for such hardware is another. ANITA (Analysing Interferometer for Ambient Air) is just one example. ANITA was a detector that could detect up to 32 different chemical compounds in the cabin air. During its operation aboard the station in 2007 and 2008, the device, which was mainly developed by the Germany based company Kayser-Threde $\mathrm{GmbH}$, helped to bridge critical but typical intervals of no atmospheric control by the U.S. gas chromatograph assembly [5].

\section{Upcoming contributions of the ISS programme to future space exploration}

Today the partners of the ISS programme have committed themselves to operate the station at least until 2020. An extension of its operational lifetime beyond that date is possible. Exploration missions beyond our planet's close vicinity will also feature longer mission durations. A mission to Mars for example could take more than three years. With at least six more years in orbit, ISS offers the opportunity to have astronauts in space for prolonged periods of time. A first one-year mission of a Russian and a U.S. astronaut is planned for 2015.

In 2016 the Advanced Close Loop System (ACLS), built by EADS Astrium in Germany will launch to the station. It is a new type of ECLS (Environmental Control and Life Support) system which will extract carbon dioxide $\left(\mathrm{CO}_{2}\right)$ from the cabin air and subsequently converts that $\mathrm{CO}_{2}$ to methane $\left(\mathrm{CH}_{4}\right)$ and water $\left(\mathrm{H}_{2} \mathrm{O}\right)$ using a Sabatier reactor. An electrolyzer will then produce oxygen $\left(\mathrm{O}_{2}\right)$ and hydrogen $\left(\mathrm{H}_{2}\right)$ from that water. Thus the oxygen can be fed back into the cabin air. The recycling process is supposed to save up to $450 \mathrm{~kg}$ of supplies each year [6]. DLR is also funding research into physico-chemical systems with biological components which could close the ECLS loop even further. A prototype of this technology could be tested aboard the 


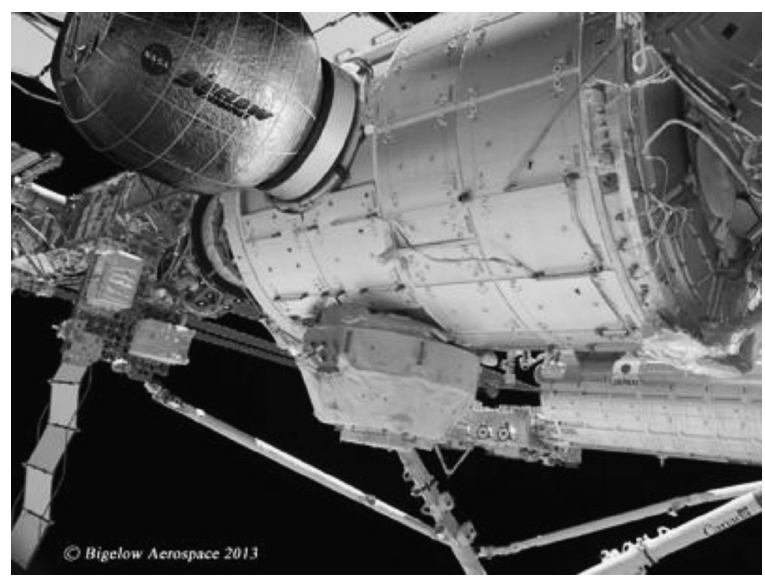

Fig. 3. Artist's Impression of BEAM docked to ISS Source: Bigelow Aerospace

station one day. Reducing the need for supplies throughout a mission is the goal of these systems. Converting the ANITA experiment into continuously running system hardware is another option which is under consideration. All these systems could be used for future exploration missions once they have proven their reliability on ISS.

Worldwide, the plans for exploration beyond LEO are still very vague. NASA is no exception as it has some tentative ideas about what will come next, but it still lacks a comprehensive roadmap. Nevertheless, NASA seems to have recognized the potential that ISS is offering as a testbed for exploration technologies. For example, NASA will test a 3D printer aboard the station in 2014. 3D printing is getting more and more popular in terrestrial applications and it shows some promising potential for application in space missions. The idea of printing your own, custom made, spare parts or eventually even food could revolutionize logistics for space operations [7].

Expandable structures are also a technology that could become important for future human missions far beyond our planet. NASA will test such a module, the Bigelow Expendable Activity Module (BEAM) at the station. The BEAM, which will be manufactured by the U.S. company Bigelow Aerospace, is supposed to be launched to ISS in 2015 and to be docked to the station for at least two years [8]. Fig. 3.

Travelling to destinations outside the Earth-Moon system takes a long time. Cutting those long travel times is a primary goal of current space propulsion research. One candidate to propel future exploration missions is the VASIMIR (Variable Specific Impulse Magnetoplasma Rocket) engine. It is planned to test a $200 \mathrm{~kW}$ version of this engine at the ISS for adjusting the station's declining orbit [9].

Missions to the Moon, an Asteroid or even Mars will also require new space suites as the current generation was primarily designed for Space Shuttle and space station operations. Testing those new space suits is expected to happen later this decade also at ISS.

NASA's Commercial Crew Program (CCP) is supposed to result in one or two new crew spacecrafts, possibly by 2017. These vehicles will not be designed to fly beyond

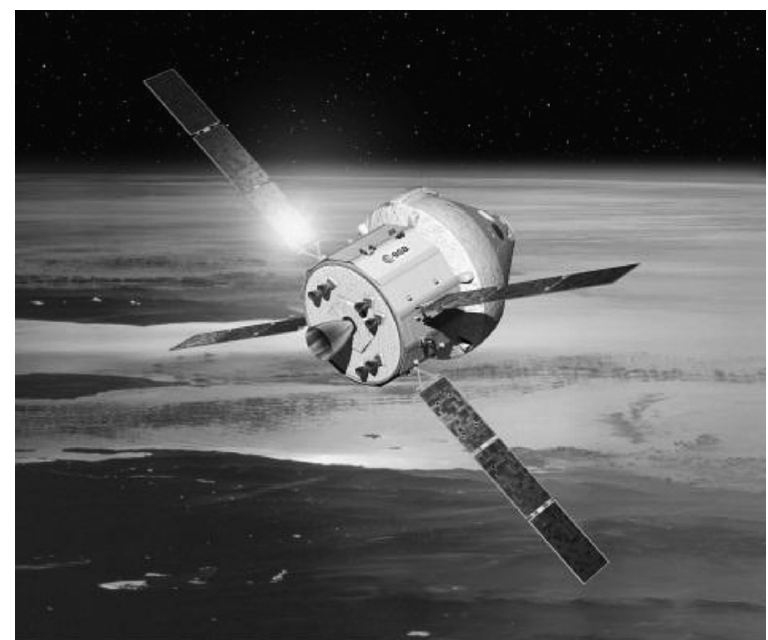

Fig. 4. Artist's Impression of the U.S. MPCV with ESM with Unfolded Solar Arrays.

Source: ESA

LEO, but the process will foster U.S. space industry and maybe one day, one of those vehicles could be upgraded to ferry astronauts to a new station at one of the EMLs or on the Moon, too. Adapting the two commercial cargo vehicles for exploration missions seems even more probable; especially if you think about supporting some kind of gateway space station at EML1 for example. One vehicle from the ISS programme that will serve as the base design for future exploration architecture is the European ATV. At the Ministerial Conference in November 2012 it was decided to develop a European Service Module (ESM) for the U.S. Multi-purpose Crew Vehicle (MPCV). The ESM will be based on ATV technology and will be developed by the same prime contractor. Airbus Defence \& Space in Bremen (Germany) will be responsible for developing and producing the first flight unit of the ESM which will be launched together with the U.S. Orion crew capsule on Exploration Mission 1 (EM-1) in late 2017. The MPCV will be NASA's vehicle for human exploration missions to destinations beyond ISS. This cooperation is a good example of how the trust and the knowledge that have been build up during the ISS programme will support space exploration in the future Fig. 4.

The modules of ISS also have the potential to be used in exploration missions. Some propose to separate some of the actual modules of ISS after the end of its lifetime and to use them for building a new station possibly at one of the EMLs. It is uncertain if that would be possible and efficient considering the advanced age of the hardware. Nevertheless, the design of the modules will definitely influence future modular space stations or deeps space habitats.

There are also proposals of assembling an Exploration Platform (EP) at ISS and subsequently moving it to its destination at EML1 or EML2 after completion [10]. In such an approach assembly of the EP could be assisted by astronaut EVAs and check-out of the completed system could be done in space before its launch to its final destination. This would decrease the risk associated of a direct launch to distant destinations. 


\section{Conclusions}

In August 2013, ISECG published a new version of its Global Exploration Roadmap (GER). Although it is not a politically binding document for the participating space agencies, it helps coordinating space exploration efforts worldwide. At the moment, no nation has a detailed plan of how to continue with human space exploration beyond ISS on the long-term. A push for a real commitment is needed.

An agreed upon roadmap would allow participating space agencies to prepare for the next steps in a meaningful way. Once we have defined the goals and ways to get there, ISS should be the prime testbed and preparation platform for many technologies and operational routines needed. The ISS programme has proven its value for scientific research in micro-gravity and a space environment. It yielded magnificent results that can change life on Earth and a lot more can be expected during the next six or more years. But using the ISS to prepare future exploration missions to more distant destinations would make that investment even more worthwhile. Some things have already been done, but much more is possible. It is the author's opinion that using the ISS for exploration preparation will also engage the general public in a new way. For many people it is difficult to understand what the scientific research that is done on ISS means to their everyday life, but exploring the solar system always catches the public's attention, as could be seen during the early weeks after the landing of the Mars Science
Laboratory (MSL) on the surface of Mars. Seeing astronauts testing new technologies and preparing themselves for future missions may make more sense to big parts of the general public.

\section{References}

[1] Petra Frings-Meuthen, Scott Smith, Martina Heer, 2011, ISS-Experiment SOLO: Auswirkungen einer hohen Kochsalzzufuhr auf den Elektrolythaushalt und den Knochenstoffwechsel in Schwerelosigkeit, Proceedings of the 49th Annual Meeting Deutsche Gesellschaft für Luft- und Raumfahrtmedizin, Sinsheim, Germany.

[2] NASA, 2013, International Space Station Utilization Statistics.

[3] NASA, 2011, The ISS to Date, 〈http://www.nasa.gov/mission_pages/ station/structure/isstodate.html (retrieved 30.05.13).

[4] DLR, 2011, DLR-Roboterarm ROKVISS aus dem All zurück, 〈http:// www.dlr.de/dlr/presse/desktopdefault.aspx/tabid-10312/ 475_read-1564/year-all $>$ (retrieved 30.05.13).

[5] Atle Honne, et al., Evaluation of ANITA Air Monitoring on the International Space Station, SAE Int. J. Aerosp. 4 (1) (2011) 451-466.

[6] Klaus Bockstahler et. al., 2011, ACLS - the Advanced Closed-Loop System for Accommodation on the ISS, in: Proceedings of the 62nd International Astronautical Congress 2011, Cape Town, South Africa.

[7] NASA, 2013, Fact Sheet 3D Printing In Zero-G Technology Demonstration (3D Printing In Zero-G), 〈http://www.nasa.gov/mission pages/station/research/experiments/1115.html (retrieved 30.05.13).

[8] NASA, 2013, Feature NASA to Test Bigelow Expandable Module on Space Station, 〈http://www.nasa.gov/mission_pages/station/news/ beam_feature.html $\rangle$ (retrieved 30.05.13).

[9] Ad Astra Rocket Company, VF-200, 〈http://www.adastrarocket.com/ aarc/VF-200> (retrieved 04.06.14).

[10] Michael Raftery, 2012, Exploration platform in the earth-moon liberation system based on ISS, in: Proceedings of the 63rd International Astronautical Congress 2012, Naples, Italy. 